\title{
Radiologic approach to axial spondyloarthritis: where are we now and where are we heading?
}

\author{
Iwona Kucybała ${ }^{1}$ (D) Andrzej Urbanik ${ }^{1}$ (D) $\cdot$ Wadim Wojciechowski $^{1,2}$ (D)
}

Received: 16 July 2018 / Accepted: 11 August 2018 / Published online: 21 August 2018

(c) The Author(s) 2018

\begin{abstract}
Current emphasis on diagnosing axial spondyloarthritis (axSpA) in early stage enforced the search for sensitive and specific diagnostic algorithms with the use of imaging methods. The aim of this review was to summarise current recommendations concerning the use of imaging techniques in diagnostics and monitoring of axSpA as well as to outline possible future directions of the development in this field. MEDLINE database was searched between March and April 2018. In the first phase, such keywords were applied: 'ASAS', 'EULAR', 'ASAS-EULAR', 'ASAS/OMERACT', 'axial spondyloarthritis', while in the second step: 'axial spondyloarthritis', 'ankylosing spondylitis', 'magnetic resonance imaging', 'computed tomography', and 'radiography', 'imaging'. An up-to-date summary of European League Against Rheumatism (EULAR) recommendations enriched with recent updates of Assessment of Spondyloarthritis International Society (ASAS) diagnostic criteria regarding imaging in axSpA course was created. Moreover, we outlined the role of new in this field, promising imaging techniques, such as diffusion-weighted imaging and dynamic contrast-enhanced sequences in magnetic resonance imaging (MRI) or lowdose computed tomography (CT). As precise monitoring of axSpA activity is vital, we reviewed the most precise methods: semiquantitative scores (e.g., Spondyloarthritis Research Consortium of Canada scores or CT Syndesmophyte Score) and quantitative analysis of MRI-based apparent diffusion coefficient or perfusion maps and enhancement curves. According to EULAR and ASAS recommendations, radiography and MRI still remain basic methods of axSpA diagnostics and monitoring. However, the knowledge of state-of-the-art international guidelines combined with the awareness of emerging imaging methods is the key to effective management of axSpA.
\end{abstract}

Keywords Sacroiliac joints · Axial spondyloarthropathy $\cdot$ Ankylosing spondylitis $\cdot$ EULAR recommendations $\cdot$ ASAS recommendations $\cdot$ Magnetic resonance imaging

\section{Introduction}

The concept of 'spondyloarthritis' describes a heterogeneous group of chronic inflammatory rheumatic diseases, which subdivides into two categories: axial (axSpA) and peripheral (pSpA) spondyloarthropathies [1,2]. The former group,

Wadim Wojciechowski

wadim.wojciechowski@uj.edu.pl

Iwona Kucybała

iwona.kucybala@gmail.com

Andrzej Urbanik

aurbanik@mp.pl

1 Chair of Radiology, Jagiellonian University Medical College, 19 Kopernika Street, 31-501 Kraków, Poland

2 Comarch Healthcare S.A., 29 Życzkowskiego Street, 31-864 Kraków, Poland
axSpA, gathers broader spectrum of states involving the sacroiliac joints (SIJs) and the spine-ankylosing spondylitis (AS) and non-radiographic axSpA [3].

Since the major symptom of the axSpA is chronic back pain, which is highly prevalent in population and not specific, it became obvious that definite diagnostic criteria had to be established [3]. Apart from clinical symptoms, radiological findings have been integral part of the AS diagnosis since the 1930s-especially detected on the SIJs radiography, as it is the point of disease origin in almost all cases of AS. The first official set of AS diagnostic criteria, which included radiological assessment of the SIJs, was the modified New York (mNY) criteria, published in 1984. Later on, the Amor (1990) and European Spondyloarthropathy Study Group criteria (1991), created for the diagnosis of spondyloarthropathies in general, contained the same definition of sacroiliitis as mNY criteria [4]. 
Nonetheless, it was the Assessment of Spondyloarthritis International Society (ASAS) criteria for axSpA (2009) which triggered real breakthrough in diagnostics of this disabling condition. The creation of separate diagnostic arm based on the radiological visualisation of sacroiliitis and incorporating magnetic resonance imaging (MRI) as a sufficient method of SIJ inflammation detection, put enormous emphasis on the importance of radiology in the diagnosis of axSpA [5]. Capturing the disease on early, preradiographical stage, what became possible owing to MRI, is especially relevant in term of quick implementation of effective therapy-namely, TNF inhibitors, which are approved in Europe also for non-radiographic axSpA [6].

On the other hand, a lot of authors criticise the ASAS criteria [6-9], predominantly because of heterogeneity in clinical characteristics and response to TNF inhibitors between populations diagnosed by imaging and clinical arms [8]. Another raised question is a tendency to lower specificity of imaging arm in previously unselected population with chronic back pain, as lesions of mechanical origin may mimic changes characteristic for axSpA on MRI [9]. Thus, staying up-to-date with current recommendations of international societies (e. g., European League Against Rheumatism-EULAR, ASAS) and regular search for more and more specific methods of axSpA evaluation is crucial for physicians dealing with this subject professionally.

The aim of this review was to summarise current recommendations regarding the use of imaging methods in diagnostics and monitoring of axSpA and to outline possible future directions of development in this field which may improve an effectiveness of early axSpA detection.

\section{Search strategy}

A comprehensive search of the MEDLINE database was conducted in the period between March and April 2018. The final search was carried out on 6 April 2018. Only published data written in English was taken into account. In the first phase of the search, such keywords were applied as 'ASAS' or 'EULAR' or 'ASAS-EULAR' or 'ASAS/OMERACT' and 'axial spondyloarthritis' to obtain only up-to-date recommendations of international societies regarding the use of imaging in diagnosis and management of axial spondyloarthritis. Preference was given to the sources published within the past 9 years. In the next step, the search was conducted with the use of the following keywords: 'axial spondyloarthritis' or 'ankylosing spondylitis' and 'magnetic resonance imaging' or 'computed tomography' or 'radiography' or 'imaging'. Titles and abstracts were analysed to identify articles covering the topic of promising imaging methods which have not been investigated thoroughly yet in the field of axSpA as well as quantitative and semiquantitative methods of axSpA assessment with the use of imaging. In this case, preference was given to articles published since 2005 . In addition, reference lists of articles which met inclusion criteria in both cases were screened for other eligible studies.

\section{Assessment of the sacroiliac joints}

\section{Conventional radiography (CR)}

According to EULAR recommendations (2015) [1]:

1. CR of the SIJs is advised as the first imaging technique to diagnose sacroiliitis associated with axSpA.

2. CR of the SIJs may be used for long-term structural damage monitoring in axSpA—especially new bone formation.

The radiographic definition of axSpA-related sacroiliitis currently used in EULAR recommendations and the imaging arm of ASAS axSpA diagnostic criteria, which is equal to $\mathrm{mNY}$ criteria, is [5]:

1. Bilateral sacroiliitis grade $\geq$ II.

2. Unilateral sacroiliitis grade $\geq$ III.

Details regarding particular grades are shown in Table 1 [4].

The primary drawback of CR in the assessment of SIJs is that it enables to visualise only late, post-inflammatory changes - capturing the disease on such advanced stage may

Table 1 Grading of radiographic sacroiliitis

\begin{tabular}{lll}
\hline Grade & Stage & Explanation \\
\hline 0 & Normal & Unchanged morphology of the joint \\
I & Suspicious & Blurring of the joint margins \\
II & Minimal abnormality & Small localised areas of erosions or sclerosis, without alteration of the joint width \\
III & Unequivocal abnormality & $\begin{array}{c}\text { Moderate/advanced sacroiliitis: } \geq 1 \text { out of: erosions, sclerosis, widening/narrow- } \\
\text { ing of the joint space, partial ankylosis }\end{array}$ \\
IV & Severe abnormality & Total ankylosis \\
\hline
\end{tabular}


significantly diminish the positive effect of biologic therapy, which is effective only with coexisting acute inflammatory changes. Moreover, due to the complex anatomy of the SIJs, multiple techniques of their visualisation and highly subjective classification of the sacroiliitis signs, the reliability of this method in less evident cases is arguable. However, up to this point, any other imaging method has not surpassed the $\mathrm{CR}$ in terms of cost-effectiveness, widespread availability, and relatively low dose of ionizing radiation. Hence, the CR most likely remains the basic modality used for sacroiliitis detection in forthcoming years [10]. There may only be an attempt made to implement more objective radiographic classification of the SIJs structural damage than existing mNY criteria.

\section{Computed tomography (CT)}

\section{According to EULAR recommendations (2015) [1]:}

1. CT might provide additional information on structural damage if CR is negative and MRI contraindicated or cannot be performed.

CT is regarded as a gold standard of the SIJs structural damage detection [11]. Nonetheless, the most important sign of active inflammation of the SIJs-bone-marrow oedemais not visible on this imaging modality. The same applies to fatty degeneration of bone marrow, which is an indicator of the early phase of chronic joint inflammation [4]. Combining aforementioned difficulties with high dose of ionizing radiation and relatively high costs, when compared to CR, reluctance towards $\mathrm{CT}$ use in diagnostics of axSpA does not come as a surprise. On the other hand, low-dose CT of the SIJs seems to be very promising technique and may have a chance to replace CR as a method of structural damage and new bone formation monitoring $[12,13]$. Another promising method is spectral CT, which enables to measure both calcium and water concentration within a tissue. As a consequence, the visualisation and quantitative analyses of the bone-marrow oedema within the SIJs are possible and this method may be a leap forward more accurate diagnosis of the $\operatorname{axSpA}[14,15]$.

\section{Magnetic resonance imaging}

According to EULAR recommendations [1]:

1. In some cases, such as young age of the patient or short symptom duration, MRI of the SIJs is an alternative to CR first imaging method of axSpA diagnosis.

2. When the diagnosis of axSpA cannot be established based on clinical features along with $\mathrm{CR}$ and axSpA is still suspected, MRI of the SIJs is recommended. Con- sider the presence of both active inflammatory lesions (bone-marrow oedema) and structural lesions (bone erosion, new bone formation, sclerosis, and fat infiltration).

3. MRI of the SIJs may be used to assess and monitor disease activity in axSpA providing additional information to clinical and biochemical assessments. The decision regarding repeating MRI depends on the clinical circumstances. Short tau inversion recovery (STIR) sequences are sufficient to detect inflammation.

4. MRI of the SIJs may provide additional information in monitoring of their structural changes.

5. Extensive MRI inflammatory activity (bone-marrow oedema) might be used as a predictor of good clinical response to anti-TNF $\alpha$ treatment in axSpA. Hence, MRI might aid in the decision of initiating biologic therapy, in addition to clinical features and CRP.

As far as axSpA diagnosis is concerned, the imaging arm of the ASAS criteria as one of the two equivalent definitions of sacroiliitis includes signs of acute inflammation highly suggestive of axSpA on MRI of the SIJs [5]. The latest update of the definition of active sacroiliitis in the course of axSpA by the ASAS MRI working group (2015) equate active inflammation on MRI only with bone-marrow oedema/osteitis and did not extend the definition of other active inflammatory lesions (such as capsulitis, synovitis, and enthesitis) or signs of chronic inflammatory changes (such as erosions, sclerosis, fat deposition, and bony bridges/ ankylosis) [4, 16]. Precise definition of bone-marrow oedema according to aforementioned criteria is a presence of bone-marrow lesion, which is hyperintense on water-sensitive T2-weighted sequences (e.g., STIR or fat-suppressed T2-weighted) or enhancing on T1-weighted sequences after the contrast media administration. If one lesion is present, it must be visible on two consecutive slices of an MRI scan, while the presence of at least two lesions on one slice is sufficient to diagnose sacroiliitis. As well, the lesion must be located in the subchondral bone in the region adjacent to articular surface of the SIJs [16]. An example of typical bone-marrow oedema lesion in the SIJs is shown in Fig. 1.

Although some authors proposed the inclusion of structural lesions to the definition of sacroiliitis highly suggestive of axSpA [17, 18], there were too many discrepancies with regard to a precise definition of these structural changes appearance on MRI to include them in the final version of the updated sacroiliitis definition. Nonetheless, in cases when it is questionable if lesions visualised on the SIJs MRI are "highly suggestive of axSpA", the evaluation of structural changes within the SIJs (especially erosions) might be beneficial for reaching the final diagnosis [16].

There exists a wide range of scoring systems facilitating quantitative evaluation of active sacroiliitis on MRI, but the best performing one is the Spondyloarthritis Research 

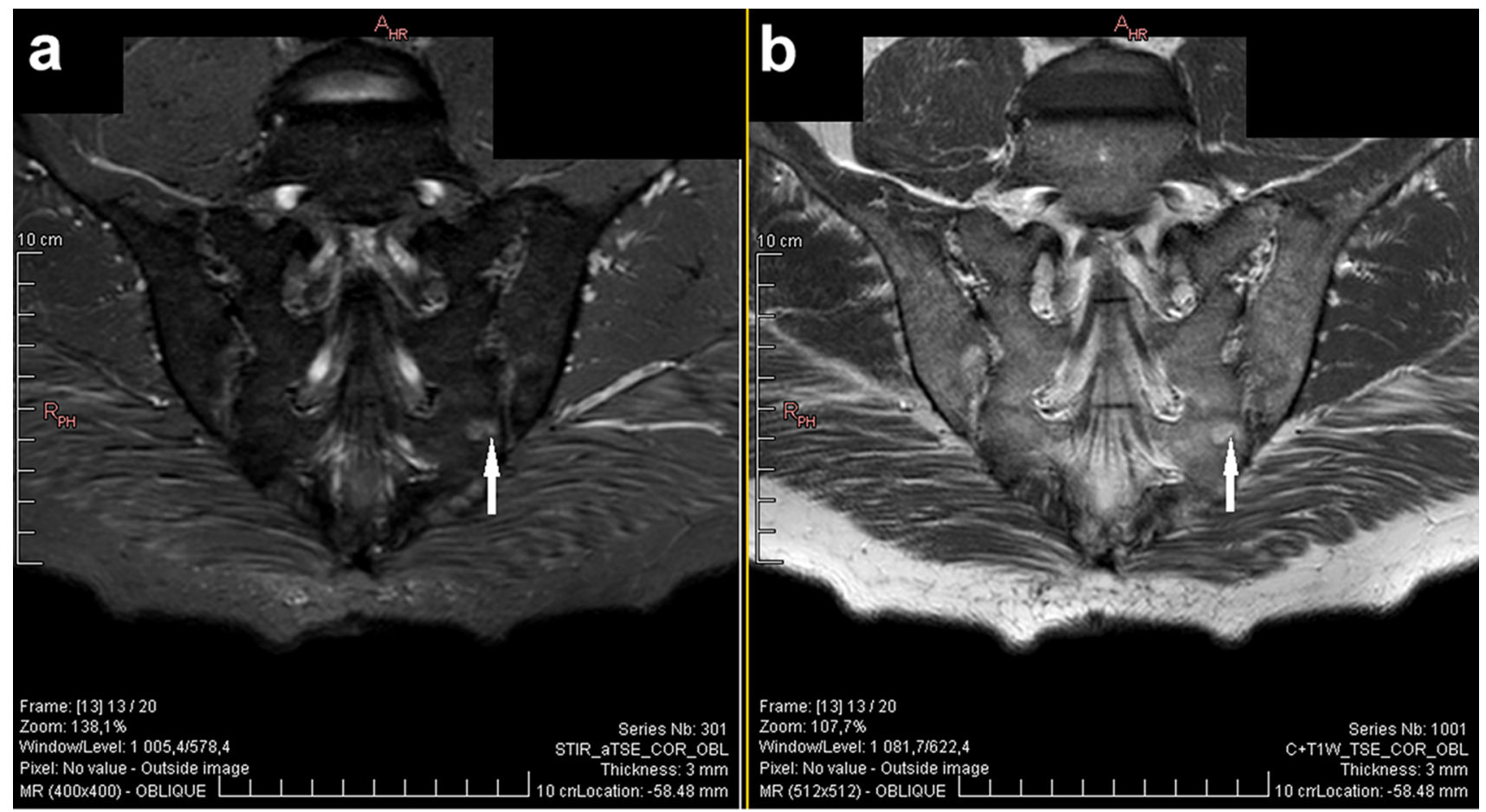

Fig. 1 Typical axSpA bone-marrow oedema lesion (white arrow) in the lower sacral quadrant of the left sacroiliac joint on STIR sequence (a) and contrast-enhanced T1-weighted sequence (b). STIR, short tau inversion recovery

Consortium of Canada (SPARCC) score [19], proposed by Maksymowych et al. [20]. This method is based on the evaluation on STIR sequence six consecutive semicoronal slices focusing on the synovial part of the SIJ, in the direction from posterior to anterior. Each SIJ is divided into four quadrants (upper iliac, lower iliac, upper sacral, and lower sacral) and every one of them is separately assessed. First, each quadrant is analysed for the presence of the hyperintense lesions in STIR sequence and scored dichotomously $(0=$ normal signal, $1=$ present lesion of increased intensity). Each quadrant could also receive an additional one point for the presence of intense signal within the lesion, and the next one for continuously increased signal for $\geq 1 \mathrm{~cm}$ from the articular surface. Summing it up, every slice maximally could get 12 points, what gives 72 points for all six slices [20]. Although assessment of the chronic inflammatory changes is not mandatory to diagnose axSpA, it is still worth performing their quantitative evaluation even for purposes of more objective disease monitoring. Analogous to previously mentioned SPARCC score for active inflammatory changes, the SPARCC MRI sacroiliac joint structural score (SSS) enables to appraise the presence of fat metaplasia, erosion, backfill, and ankylosis [21].

All current guidelines regarding the diagnostics and monitoring of the axSpA with the use of MRI advise only the use of a few basic sequences (fat-suppressed T2-weighted, STIR, fat-suppressed contrast-enhanced T1-weighted sequences).
Nevertheless, the advancement in the field of MRI imaging leads to the popularization of diffusion-weighted imaging (DWI) combined with apparent diffusion coefficient (ADC) maps, and dynamic contrast-enhanced (DCE) sequences, also in rheumatology. Example of these techniques' application in the visualisation of active inflammatory lesions of patients with axSpA is shown in Figs. 2 and 3. However, utility of both these sequences in the assessment of axSpA arouses controversy for the time being. On one hand, the majority of the current studies describes these sequences as highly sensitive methods of early sacroiliitis diagnosis and its effective differentiation, additionally enabling quantitative assessment of inflammatory changes for purposes of the disease activity monitoring [22-25]. An example of such quantitative analysis of enhancement curve within the area of active inflammatory lesion compared to unaffected area based on DCE sequence is presented in Fig. 4. On the other hand, some authors question the beneficial value of incorporating these sequences to the basic image acquisition protocol used for diagnostics of axSpA [26]. Taking into account that up to this point, the literature on this topic is very limited, the use of DWI and DCE sequences in the diagnostics, differentiation, and quantitative monitoring of the axSpA seems to be the promising topic for future research. However, DWI appears to be more beneficial, because it is fast sequence which does not require gadolinium administration. 


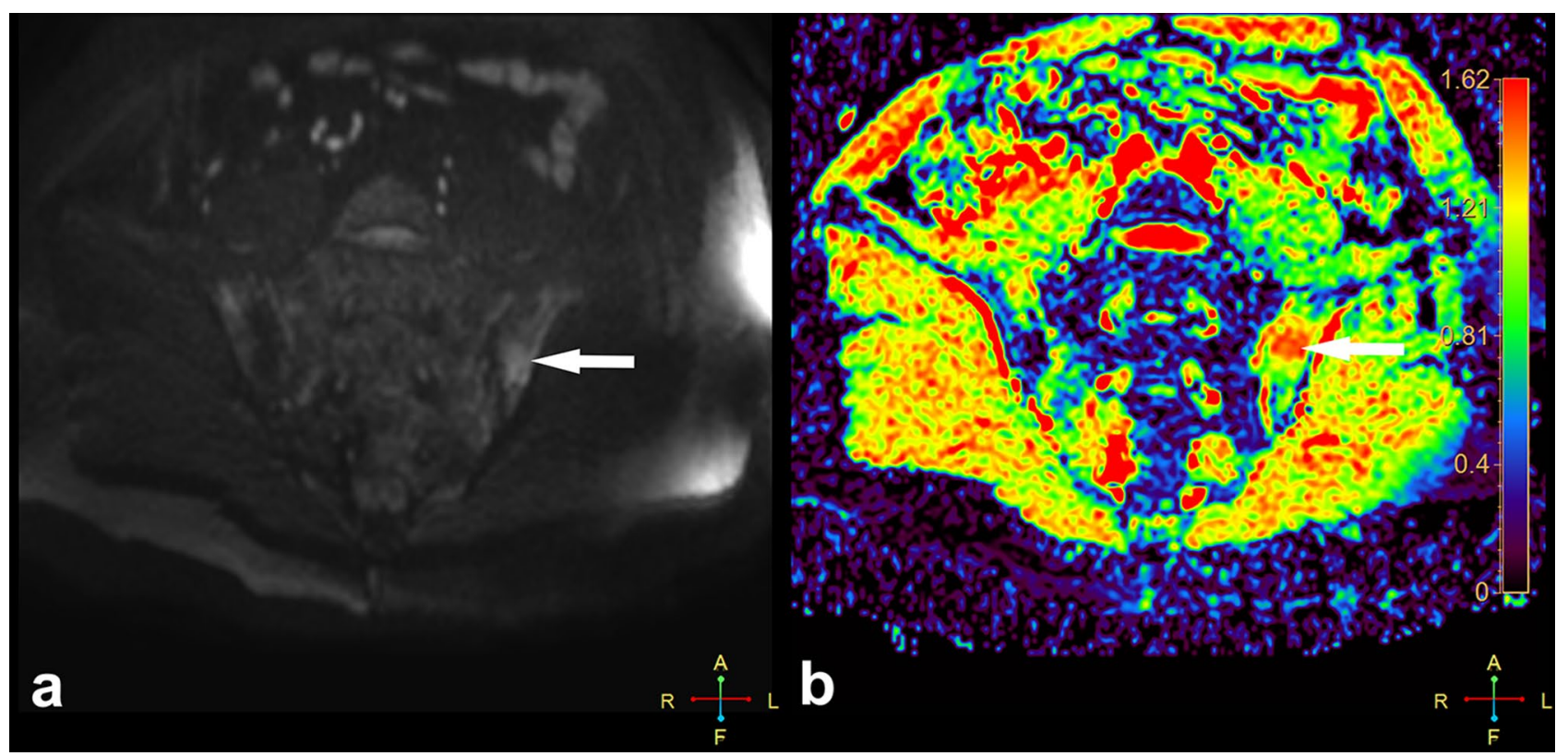

Fig. 2 Active inflammatory lesion in the course of axSpA (white arrow) located in the iliac part of the left sacroiliac joint on DWI ( $b=800)$ sequence (a) and colour ADC map (b). DWI, diffusion-weighted imaging; ADC, apparent diffusion coefficient

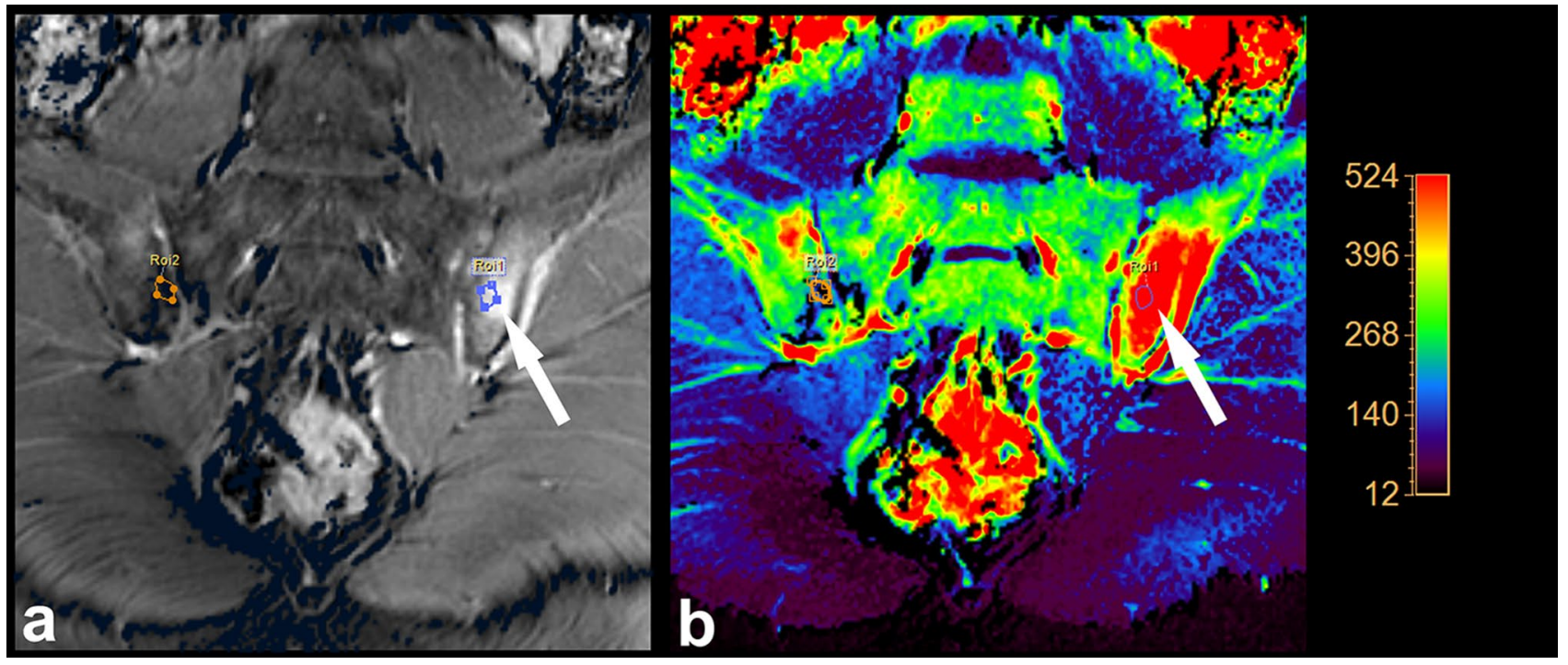

Fig. 3 Active inflammatory lesion in the course of axSpA (white arrow) situated in the iliac part of the left sacroiliac joint visualised with use of DCE sequence (a) and maximal perfusion colour-coded map (b)

Another auspicious modality which is extensively investigated in rheumatology is whole-body MRI, which allows to comprehensively evaluate axial and peripheral articular inflammatory changes along with enthesitis [27-29]. The general assessment of the whole musculoskeletal system appears as the potentially effective tool of axSpA differentiation and detailed disease activity monitoring.

\section{Other imaging modalities}

According to EULAR recommendations [1]:

1. Scintigraphy and ultrasound are not recommended for diagnosis of sacroiliitis as a part of axSpA. 


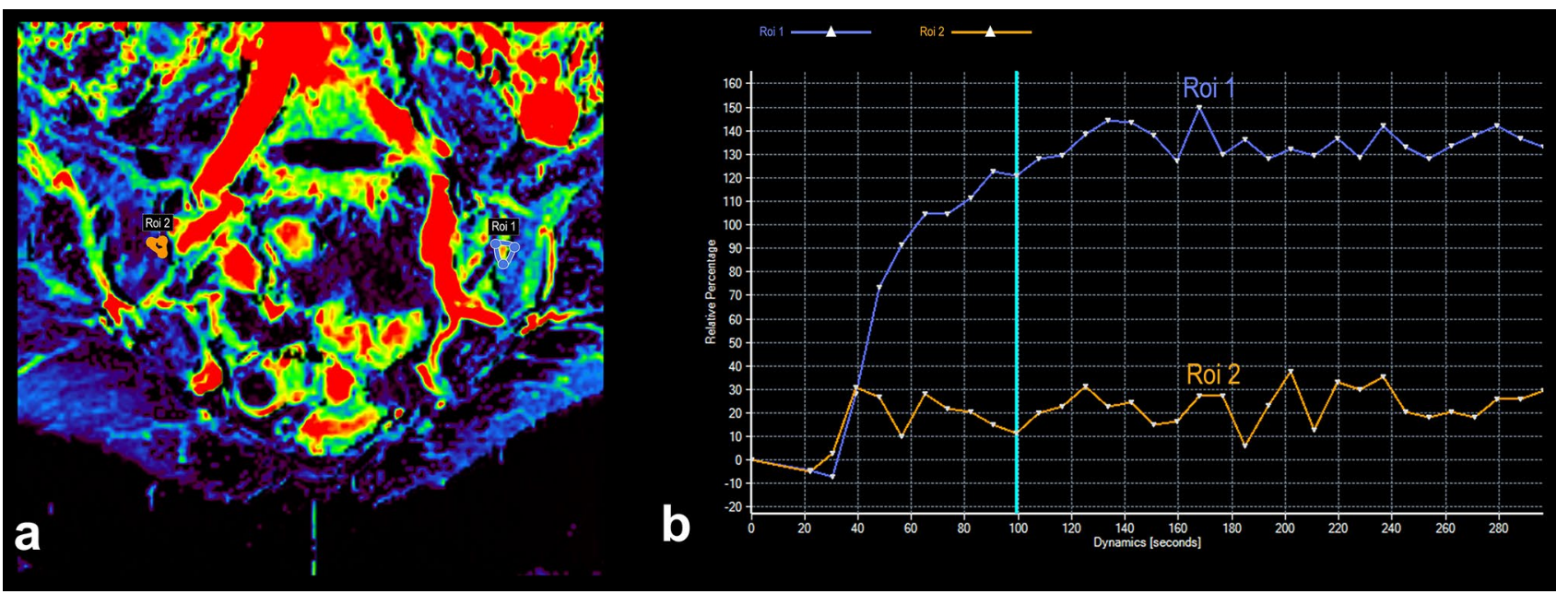

Fig. 4 Area under the perfusion curve colour-coded map of the sacral region of the person with axSpA, with marked inflammatory lesion in the upper iliac quadrant of the left sacroiliac joint (Roi 1, blue line) and respective unaffected area in the right sacroiliac joint (Roi 2, orange line) (a). The graph of relative percentage enhancement versus time of acquisition showing the pattern of enhancement in typical axSpA active inflammatory lesion (Roi 1, blue line) in comparison to intact, non-enhancing tissue (Roi 2, orange line) (b)
2. Future research agenda: investigation of new/alternative imaging technologies which may be potentially useful for clinical purposes (ultrasound-new transducers, Doppler quantification, elastosonography; new nuclear medicine techniques; optical imaging).

At this moment, recommendations do not include ultrasonography as a sufficient method of axSpA-related sacroiliitis diagnosis and monitoring. As the ultrasonography is imaging method which is the most dependent on its operator experience, when combined with the anatomic complexity of this region, it significantly limits the daily usage of this method in axSpA diagnostics and management. Nonetheless, since it allows to visualise articular and soft-tissue periarticular involvement of the SIJs, it may be considered as one of the methods facilitating early axSpA diagnosis in less evident cases [30, 31]. Colour and duplex Doppler sonography with or without the use of specific contrast media may turn out as a perfect tool for long-term monitoring of the SIJs inflammation activity and response to treatment, as it is suggested in some preliminary reports [32, 33].

Moving to nuclear medicine techniques, bone scintigraphy was widely used for axSpA-related sacroiliitis detection in the past, thanks to the capability of illustrating the regions of inflammation and high bone turnover within the SIJs. Nevertheless, this technique was superseded by MRI, as a consequence of its low sensitivity, specificity, and accuracy [31]. Popularization of the hybrid imaging methods in rheumatology may be a new hope of early axSpA diagnosis. Up to this point, few studies focusing on the use of ${ }^{18} \mathrm{~F}$-PET/ $\mathrm{MR}$ and ${ }^{18} \mathrm{~F}-\mathrm{PET} / \mathrm{CT}$ were published. Although the data on the utility of these methods in the field of axSpA are sparse, yet they suggest that they may be advantageous in terms of detection of future new bone formation areas (visualisation of osteoblastic activity and hyperaemia) and assessment of disease activity [34-36].

\section{Assessment of the spine}

\section{Conventional radiography}

According to EULAR recommendations [1]:

1. CR of the spine might be used for long-term monitoring of structural damage in $\operatorname{axSpA}$, especially new bone formation.

2. In patients with $\mathrm{AS}$, initial CR of the lumbar and cervical spine is recommended to detect syndesmophytes, which are predictors of new syndesmophytes formation.

The role of the CR of the spine in fact is limited to the monitoring of late stage of axSpA progression, namely, AS, as only chronic changes, such as ankylosis and syndesmophytes, are visible there [4]. As far as semiquantitative methods of spinal structural changes scoring is concerned, the most popular and reliable one is the modified Stoke Ankylosing Spondylitis Spinal Score (mSASSS) [4]. This method of evaluation base on the assessment of anterior corners of cervical and lumbar spine vertebrae in the lateral viewfrom the lower border of $\mathrm{C} 2$ to the upper border of Th1 and from the lower border of Th12 to the upper border of S1 (including). Each corner is scored from the 0 to 3 points, depending on its morphology ( 0 -normal; 1 -sclerosis, 
squaring or erosion; 2-syndesmophyte; 3 -bony bridge), and the maximal possible score is 72 points [4].

\section{Computed tomography}

CT of the spine is not included in any set of recommendations as an advised method of the spine structural damage assessment. In general, it is understandable, taking into account the extremely high dose of ionizing radiation during CT examination of such large area as the spine and satisfactory performance of spine CR. Nonetheless, CR assessment, especially only with the use of the mSASSS score, omits evaluation of frequently affected by axSpA thoracic vertebrae as well as posterior vertebral corners and facet joints. In addition, the imprecise character of CR images hinders the short-term progression evaluation, as it may take up to 2 years to observe axSpA radiographic progression [13]. These drawbacks of CR lead to the development in the field of low-dose CT as a possible method of chronic bony changes assessment in the spine. This technique detects significantly more bony proliferation lesions than $\mathrm{CR}$ combined with the mSASSS scoring system [37].

Newly proposed CT Syndesmophyte Score (CTSS) seems to be a reliable tool for precise assessment of new bone formation in the course of AS with the use of low-dose CT [38]. The spine is analysed in two planes: sagittal and coronal, where the anterior + posterior rim and the right + left rim are assessed, respectively - in summary four quadrants. Every vertebra is additionally divided in upper and lower half, which are evaluated separately. The score takes into account the area from the bottom half of the $\mathrm{C} 2$ vertebra to the upper half of S1 vertebra (including). Every quadrant of vertebrae half is scored with 0 to 3 points-details concerning the rules of scoring are demonstrated in Table 2. Maximal possible score is 552 points [38]. This method, apart from the precise monitoring of AS progression, enables to quantitatively analyse the effect of biological therapy on new syndesmophytes formation.

\section{Magnetic resonance imaging}

According to EULAR recommendations [1]:

Table 2 Scoring system of syndesmophytes according to the CT Syndesmophyte Score

\begin{tabular}{ll}
\hline Score & Description of changes \\
\hline 0 & Syndesmophyte absent \\
1 & Syndesmophyte reaches $<50 \%$ of the intervertebral disc space \\
2 & $\begin{array}{l}\text { Syndesmophyte reaches } \geq 50 \% \text { of the intervertebral disc } \\
\text { space, but does not form the bridge }\end{array}$ \\
3 & Syndesmophyte bridge \\
\hline
\end{tabular}

1. MRI of the spine is not generally recommended in the diagnostics of axSpA.

2. MRI of the spine may be used to evaluate and monitor the axSpA activity, providing additional information to clinical and biochemical assessments.

3. MRI of the spine may be used to predict development of new, radiographic syndesmophytes-especially relevant are such changes as vertebral corner inflammatory or fatty lesions.

4. Extensive inflammatory activity, particularly on MRI of the spine of patients with AS, may be used as a predictor of good clinical response to anti-TNF $\alpha$ treatment in axSpA. As well, it may aid the decision of starting biologic therapy, in addition to clinical examination and CRP.

The principal active inflammatory lesion which is detected on MRI of the spine in patients with axSpA is bonemarrow oedema in the area adjacent to: anterior and posterior corners of vertebrae (spondylitis), vertebral endplates (spondylodiscitis), insertions of the anterior and posterior longitudinal ligaments (osteitis related to enthesitis), or facet and costovertebral joints (arthritis). As well, enthesitis of the spinal ligaments may be visible. Chronic inflammatory changes, which could appear in the course of axSpA, are: fat deposition on vertebral corners, erosions, syndesmophytes, and ankylosis [4, 39]. However, according to ASAS consensus (2012), it is the anterior and posterior spondylitis along with fatty depositions on vertebral corners which are lesions typical for axSpA. If anterior/posterior spondylitis is located in three or more sites in the spine and fatty depositions on several vertebral corners, they could be classified as highly suggestive of axSpA, especially in younger patients. The rest of inflammatory or structural changes are either non-specific or not sufficiently investigated yet to include them in final consensus [39]. Nonetheless, the assessment of MRI of the spine may only play supporting role in the diagnostics of the axSpA. The ASAS MRI working group did not recommend adding MRI of the spine into the definition of positive, suggestive of axSpA MRI as not beneficial for reaching the diagnosis, since the group of patients with positive MRI of the spine and negative MRI of the SIJ is marginal [16, 40]. Yet, it still could be a great method of disease activity and response to treatment monitoring.

Analogical to the one applying to MRI of the SIJs, there is a quantitative analysis method dedicated to the spine, called SPARCC spine inflammation score. Discovertebral units, namely, an intervertebral disc and adjacent endplates, are divided into four quadrants: lower anterior, lower posterior, upper anterior, and upper posterior endplates. If the increased signal is identified in particular quadrant, it receives 1 point, if not, 0 points. One additional point could be added for the presence of intense signal and another for 
the lesion $\geq 1 \mathrm{~cm}$ in depth. Each quadrant is assessed in three consecutive sagittal slices, which gives a maximal score of 18 per whole discovertebral unit. This method of evaluation should be applied to 6 affected discovertebral units, and therefore, the maximal possible score is 108 points. The whole analysis should be performed on fat-suppressed T2-weighted or STIR sequence [41].

Basic sequences used for the spine imaging in MR are: T1-weighted, fat-suppressed T2-weighted, STIR, and postgadolinium fat-suppressed T1-weighted sequence [39]. The role of other sequences, such as DWI and DCE, is almost unexplored yet. There is only one report on this topic [42], which suggest that DWI is a sensitive and quick method of spinal active inflammatory changes' evaluation. This remains another prospective branch which may significantly facilitate diagnosis and progression monitoring of axSpA in future.

\section{Conclusion}

According to the EULAR and ASAS recommendations, conventional radiography and magnetic resonance imaging remain the basic methods of axSpA diagnosis, monitoring and response to treatment assessment. However, there is still a need to search for more accurate methods of early diagnosis and progression assessment, and alternative MRI sequences (DWI, DCE sequences), low-dose CT and hybrid imaging may be these missing links.

Author contributions WW conceived the article concept and design. IK was responsible for literature research, writing the article, and preparation of illustrations. WW and AU participated in critical revision of the article. All authors read and approved the final manuscript.

\section{Compliance with ethical standards}

Conflict of interest All authors declare that they have no conflict of interest.

Ethical approval This article does not contain any studies with human participants performed by any of the authors.

Open Access This article is distributed under the terms of the Creative Commons Attribution 4.0 International License (http://creativeco mmons.org/licenses/by/4.0/), which permits unrestricted use, distribution, and reproduction in any medium, provided you give appropriate credit to the original author(s) and the source, provide a link to the Creative Commons license, and indicate if changes were made.

\section{References}

1. Mandl P, Navarro-Compán V, Terslev L et al (2015) EULAR recommendations for the use of imaging in the diagnosis and management of spondyloarthritis in clinical practice. Ann Rheum Dis 74:1327-1339. https://doi.org/10.1136/annrheumdis-2014-20697 1

2. Rudwaleit M, Jurik AG, Hermann KG, Landewé R, van der Heijde D, Baraliakos X, Marzo-Ortega H, Ostergaard M, Braun J, Sieper J (2009) Defining active sacroiliitis on magnetic resonance imaging (MRI) for classification of axial spondyloarthritis: a consensual approach by the ASAS/OMERACT MRI group. Ann Rheum Dis 68:1520-1527. https://doi.org/10.1136/ ard.2009.110767

3. van der Heijde D, Ramiro S, Landewé R et al (2017) 2016 update of the ASAS-EULAR management recommendations for axial spondyloarthritis. Ann Rheum Dis 76:978-991. https://doi. org/10.1136/annrheumdis-2016-210770

4. Sieper J, Rudwaleit M, Baraliakos X, Brandt J, Braun J, BurgosVargas R, Dougados M, Hermann KG, Landewé R, Maksymowych W, van der Heijde D (2009) The Assessment of SpondyloArthritis international Society (ASAS) handbook: a guide to assess spondyloarthritis. Ann Rheum Dis 68(Suppl 2):ii1-i44. https:// doi.org/10.1136/ard.2008.104018

5. Rudwaleit M, van der Heijde D, Landewé R et al (2009) The development of Assessment of SpondyloArthritis international Society classification criteria for axial spondyloarthritis (part II): validation and final selection. Ann Rheum Dis 68:777-783. https ://doi.org/10.1136/ard.2009.108233

6. Akkoc N, Khan MA (2015) Looking into the new ASAS classification criteria for axial spondyloarthritis through the other side of the glass. Curr Rheumatol Rep 17:515. https://doi.org/10.1007/ s11926-015-0515-2

7. Akkoc N, Khan MA (2016) ASAS classification criteria for axial spondyloarthritis: time to modify. Clin Rheumatol 35:1415-1423. https://doi.org/10.1007/s10067-016-3261-6

8. van der Linden S, Akkoc N, Brown MA, Robinson PC, Khan MA (2015) The ASAS criteria for axial spondyloarthritis: strengths, weaknesses, and proposals for a way forward. Curr Rheumatol Rep 17:62. https://doi.org/10.1007/s11926-015-0535-y

9. Dubreuil M, Deodhar AA (2017) Axial spondyloarthritis classification criteria: the debate continues. Curr Opin Rheumatol 29:317-322. https://doi.org/10.1097/BOR.0000000000000402

10. Poddubnyy D (2017) Radiographic evaluation of sacroiliac joints in axial spondyloarthritis—still worth performing? J Rheumatol 44:1-3. https://doi.org/10.3899/jrheum.161232

11. Baraliakos X, Braun J (2013) Opinion: Perspectives on imaging in axial spondyloarthritis. Nat Rev Rheumatol 9:498-502. https ://doi.org/10.1038/nrrheum.2013.83

12. Gao D, Li KP, Wen QF, Zhu J, Zhang JL, Huang F (2016) A preliminary exploration of low-dose semicoronal CT of the sacroiliac joints in the diagnosis of ankylosing spondylitis. Zhonghua Nei Ke Za Zhi 55:355-360. https://doi.org/10.3760/cma.j.i ssn.0578-1426.2016.05.005

13. Maksymowych WP, Lambert RG (2018) Spondyloarthritis: lowdose CT for spondyloarthritis - a brilliant new chapter? Nat Rev Rheumatol 14:130-131. https://doi.org/10.1038/nrrheum.2018.4

14. Zhang P, Yu KH, Guo RM, Ran J, Liu Y, Morelli J, Runge VM, Li XM (2016) A novel diagnostic method (spectral computed tomography of sacroiliac joints) for axial spondyloarthritis. J Formos Med Assoc 115:658-664. https://doi.org/10.1016/j. jfma.2015.07.003

15. Zhang P, Yu KH, Guo RM, Ran J, Liu Y, Morelli J, Runge VM, Li XM (2016) Comparing the diagnostic utility of sacroiliac spectral 
CT and MRI in axial spondyloarthritis. Br J Radiol 89:20150196. https://doi.org/10.1259/bjr.20150196

16. Lambert RG, Bakker PA, van der Heijde D et al (2016) Defining active sacroiliitis on MRI for classification of axial spondyloarthritis: update by the ASAS MRI working group. Ann Rheum Dis 75:1958-1963. https://doi.org/10.1136/annrheumdis-2015-20864 2

17. Weber U, Østergaard M, Lambert RG, Pedersen SJ, Chan SM, Zubler V, Rufibach K, Zhao Z, Maksymowych WP (2015) Candidate lesion-based criteria for defining a positive sacroiliac joint MRI in two cohorts of patients with axial spondyloarthritis. Ann Rheum Dis 74:1976-1982. https://doi.org/10.1136/annrheumdi s-2014-205408

18. de Hooge M, van den Berg R, Navarro-Compán V, Reijnierse M, van Gaalen F, Fagerli K, Landewé R, van Oosterhout M, Ramonda R, Huizinga T, van der Heijde D (2016) Patients with chronic back pain of short duration from the SPACE cohort: which MRI structural lesions in the sacroiliac joints and inflammatory and structural lesions in the spine are most specific for axial spondyloarthritis? Ann Rheum Dis 75:1308-1314. https://doi.org/10.1136/ annrheumdis-2015-207823

19. Landewé RB, Hermann KG, van der Heijde DM et al (2005) Scoring sacroiliac joints by magnetic resonance imaging. A multiplereader reliability experiment. J Rheumatol 32:2050-2055

20. Maksymowych WP, Inman RD, Salonen D, Dhillon SS, Williams M, Stone M, Conner-Spady B, Palsat J, Lambert RG (2005) Spondyloarthritis research Consortium of Canada magnetic resonance imaging index for assessment of sacroiliac joint inflammation in ankylosing spondylitis. Arthritis Rheum 53:703-709. https://doi. org/10.1002/art.21445

21. Maksymowych WP, Wichuk S, Chiowchanwisawakit P, Lambert RG, Pedersen SJ (2015) Development and preliminary validation of the spondyloarthritis research consortium of Canada magnetic resonance imaging sacroiliac joint structural score. J Rheumatol 42:79-86. https://doi.org/10.3899/jrheum.140519

22. Gaspersic N, Sersa I, Jevtic V, Tomsic M, Praprotnik S (2008) Monitoring ankylosing spondylitis therapy by dynamic contrastenhanced and diffusion-weighted magnetic resonance imaging. Skeletal Radiol 37:123-131. https://doi.org/10.1007/s0025 6-007-0407-2

23. Zhang M, Zhou L, Huang N, Zeng H, Liu S, Liu L (2017) Assessment of active and inactive sacroiliitis in patients with ankylosing spondylitis using quantitative dynamic contrast-enhanced MRI. J Magn Reson Imaging 46:71-78. https://doi.org/10.1002/ jmri.25559

24. Ai F, Ai T, Li X, Hu D, Zhang W, Morelli JN (2012) Value of diffusion-weighted magnetic resonance imaging in early diagnosis of ankylosing spondylitis. Rheumatol Int 32:4005-4013. https:// doi.org/10.1007/s00296-011-2333-9

25. Sahin N, Hacibeyoglu H, Ince O, Solak A, Uyar B, Erol O, Uslu ZA, Kobak S (2015) Is there a role for DWI in the diagnosis of sacroiliitis based on ASAS criteria? Int J Clin Exp Med 8:7544-7552

26. Boy FN, Kayhan A, Karakas HM, Unlu-Ozkan F, Silte D, Aktas I (2014) The role of multi-parametric MR imaging in the detection of early inflammatory sacroiliitis according to ASAS criteria. Eur J Radiol 83:989-996. https://doi.org/10.1016/j.ejrad.2014.03.002

27. Song IH, Hermann KG, Haibel H, Althoff CE, Poddubnyy D, Listing J, Weiß A, Freundlich B, Lange E, Rudwaleit M, Sieper J (2016) Inflammatory and fatty lesions in the spine and sacroiliac joints on whole-body MRI in early axial spondyloarthritis-3-year data of the ESTHER trial. Semin Arthritis Rheum 45:404-410. https://doi.org/10.1016/j.semarthrit.2015.08.005

28. Poggenborg RP, Eshed I, Østergaard M, Sørensen IJ, Møller JM, Madsen OR, Pedersen SJ (2015) Enthesitis in patients with psoriatic arthritis, axial spondyloarthritis and healthy subjects assessed by 'head-to-toe' whole-body MRI and clinical examination. Ann Rheum Dis 74:823-829. https://doi.org/10.1136/annrheumdi s-2013-204239

29. Weber U, Hodler J, Jurik AG, Pfirrmann CW, Rufibach K, Kissling RO, Khan MA, Lambert RG, Maksymowych WP (2010) Assessment of active spinal inflammatory changes in patients with axial spondyloarthritis: validation of whole body MRI against conventional MRI. Ann Rheum Dis 69:648-653. https://doi.org/10.1136/ ard.2009.108274

30. Bandinelli F, Melchiorre D, Scazzariello F, Candelieri A, Conforti D, Matucci-Cerinic M (2013) Clinical and radiological evaluation of sacroiliac joints compared with ultrasound examination in early spondyloarthritis. Rheumatology 52:1293-1297. https://doi. org/10.1093/rheumatology/ket105

31. Ran J, Morelli JN, Xie R, Zhang X, Liang X, Liu X, Li X (2017) Role for imaging in spondyloarthritis. Q J Nucl Med Mol Imaging 61:271-282. https://doi.org/10.23736/S1824-4785.17.02981-8

32. Unlü E, Pamuk ON, Cakir N (2007) Color and duplex Doppler sonography to detect sacroiliitis and spinal inflammation in ankylosing spondylitis. Can this method reveal response to anti-tumor necrosis factor therapy? J Rheumatol 34:110-116

33. Klauser A, Halpern EJ, Frauscher F, Gvozdic D, Duftner C, Springer P, Schirmer M (2005) Inflammatory low back pain: high negative predictive value of contrast-enhanced color Doppler ultrasound in the detection of inflamed sacroiliac joints. Arthritis Rheum 53:440-444. https://doi.org/10.1002/art.21161

34. Buchbender C, Ostendorf B, Ruhlmann V, Heusch P, Miese F, Beiderwellen K, Schneider M, Braun J, Antoch G, Baraliakos X (2015) Hybrid 18F-labeled fluoride positron emission tomography/magnetic resonance $(\mathrm{mr})$ imaging of the sacroiliac joints and the spine in patients with axial spondyloarthritis: a pilot study exploring the link of MR bone pathologies and increased osteoblastic activity. J Rheumatol 42:1631-1637. https://doi. org/10.3899/jrheum. 150250

35. Sawicki LM, Lütje S, Baraliakos X et al (2017) Dual-phase hybrid ${ }^{18}$ F-Fluoride Positron emission tomography/MRI in ankylosing spondylitis: investigating the link between MRI bone changes, regional hyperaemia and increased osteoblastic activity. J Med Imaging Radiat Oncol. https://doi.org/10.1111/1754-9485.12687

36. Idolazzi L, Salgarello M, Gatti D, Viapiana O, Vantaggiato E, Fassio A, Adami S, Rossini M (2016) 18F-fluoride PET/CT for detection of axial involvement in ankylosing spondylitis: correlation with disease activity. Ann Nucl Med 30:430-434. https://doi. org/10.1007/s12149-016-1080-0

37. de Koning A, de Bruin F, van den Berg R, Ramiro S, Baraliakos X, Braun J, van Gaalen FA, Reijnierse M, van der Heijde D (2018) Low-dose CT detects more progression of bone formation in comparison to conventional radiography in patients with ankylosing spondylitis: results from the SIAS cohort. Ann Rheum Dis 77:293-299. https://doi.org/10.1136/annrheumdis-2017-211989

38. de Bruin F, de Koning A, van den Berg R, Baraliakos X, Braun J, Ramiro S, van Gaalen FA, Reijnierse M, van der Heijde D (2018) Development of the CT Syndesmophyte Score (CTSS) in patients with ankylosing spondylitis: data from the SIAS cohort. Ann Rheum Dis 77:371-377. https://doi.org/10.1136/annrheumdi s-2017-212553

39. Hermann KG, Baraliakos X, van der Heijde DM et al (2012) Descriptions of spinal MRI lesions and definition of a positive MRI of the spine in axial spondyloarthritis: a consensual approach by the ASAS/OMERACT MRI study group. Ann Rheum Dis 71:1278-1288. https://doi.org/10.1136/ard.2011.150680

40. Ez-Zaitouni Z, Bakker PA, van Lunteren M et al (2017) The yield of a positive MRI of the spine as imaging criterion in the ASAS classification criteria for axial spondyloarthritis: results from the SPACE and DESIR cohorts. Ann Rheum Dis 76:1731-1736. https ://doi.org/10.1136/annrheumdis-2017-211486 
41. Maksymowych WP, Inman RD, Salonen D, Dhillon SS, Krishnananthan R, Stone M, Conner-Spady B, Palsat J, Lambert RG (2005) Spondyloarthritis Research Consortium of Canada magnetic resonance imaging index for assessment of spinal inflammation in ankylosing spondylitis. Arthritis Rheum 53:502-509. https ://doi.org/10.1002/art.21337
42. Dallaudière B, Dautry R, Preux PM, Perozziello A, Lincot J, Schouman-Claeys E, Serfaty JM (2014) Comparison of apparent diffusion coefficient in spondylarthritis axial active inflammatory lesions and type 1 Modic changes. Eur J Radiol 83:366-370. https ://doi.org/10.1016/j.ejrad.2013.10.009 